\title{
Agricultural chemicals: life changer for mosquito vectors in agricultural landscapes?
}

\author{
Tabitha W. Kibuthu*, Sammy M. Njenga ${ }^{2}$, Amos K. Mbugua ${ }^{3}$ and Ephantus J. Muturi ${ }^{4,5^{*}}$
}

\begin{abstract}
Background: Although many mosquito species develop within agricultural landscapes where they are potentially exposed to agricultural chemicals (fertilizers and pesticides), the effects of these chemicals on mosquito biology remain poorly understood. This study investigated the effects of sublethal concentrations of four agricultural chemicals on the life history traits of Anopheles arabiensis and Culex quinquefasciatus mosquitoes.

Methods: Field and laboratory experiments were conducted to examine how sublethal concentrations of four agricultural chemicals: an insecticide (cypermethrin), a herbicide (glyphosate), and two nitrogenous fertilizers (ammonium sulfate and diammonium phosphate) alter oviposition site selection, emergence rates, development time, adult body size, and longevity of An. arabiensis and CX. quinquefasciatus.

Results: Both mosquito species had preference to oviposit in fertilizer treatments relative to pesticide treatments. Emergence rates for An. arabiensis were significantly higher in the control and ammonium sulfate treatments compared to cypermethrin treatment, while emergence rates for $C x$. quinquefasciatus were significantly higher in the diammonium phosphate treatment compared to glyphosate and cypermethrin treatments. For both mosquito species, individuals from the ammonium sulfate and diammonium phosphate treatments took significantly longer time to develop compared to those from cypermethrin and glyphosate treatments. Although not always significant, males and females of both mosquito species tended to be smaller in the ammonium sulfate and diammonium phosphate treatments compared to cypermethrin and glyphosate treatments. There was no significant effect of the agrochemical treatments on the longevity of either mosquito species.

Conclusions: These results demonstrate that the widespread use of agricultural chemicals to enhance crop production can have unexpected effects on the spatial distribution and abundance of mosquito vectors of malaria and lymphatic filariasis.
\end{abstract}

Keywords: Agricultural chemicals, Sublethal concentrations, Life history traits, Anopheles arabiensis, Culex quinquefasciatus

\section{Background}

Mosquitoes transmit some of the most devastating infectious diseases including malaria, lymphatic filariasis (LF), and dengue. Transmission of these diseases is largely influenced by mosquito distribution, abundance and fitness, which are in turn dependent on the

\footnotetext{
* Correspondence: tabwamboi@yahoo.com; ephajumu@yahoo.com ${ }^{1}$ Institute of Tropical Medicine, Jomo Kenyatta University of Agriculture and Technology, Nairobi, Kenya

${ }^{4}$ Illinois Natural History Survey, Prairie Research Institute, University of Illinois, Champaign, USA

Full list of author information is available at the end of the article
}

quality of aquatic habitats where egg hatch and larval development occurs $[1,2]$. Because mosquitoes do not provide parental care to their offspring, natural selection should favor the ability of gravid females to select aquatic habitats that maximize egg hatch and offspring fitness [3]. This process requires complex integration of biological, chemical and physical cues by gravid females [4]. Chemical contaminants can potentially disrupt this process by modifying the quality and attractiveness of the aquatic habitats and vector biologists are faced with the challenge of determining 
the impact of these chemicals on mosquito ecology, behavior, and ability to transmit pathogens.

Agrochemicals (fertilizers and pesticides) are one of the major classes of chemical contaminants that can potentially affect mosquito oviposition behavior and offspring fitness. Every year, an estimated 2.4 million tons of pesticides [5] and 180.1 million tons of fertilizers [6] are used worldwide to improve agricultural production and human health. The extensive use of these chemicals has led to their recurrent detection in many surface waters $[7,8]$ increasing the potential for aquatic communities to be exposed to these chemicals. Immature stages (larvae and pupae) of many mosquito species including the vectors of malaria and LF develop in a variety of ephemeral and permanent water bodies situated within agricultural areas where they are potentially exposed to agrochemicals that are either applied to these farmlands or transported from nearby farmlands through spray drift, surface runoff, and/or leaching. However, despite the notable potential for mosquitoes to be exposed to agrochemicals, the implications of agrochemical use on the ecology and behavior of major vectors remain poorly understood.

Agricultural application of nitrogenous fertilizers is a major source of nitrate contamination of aquatic systems. In many countries, nitrate concentration in surface and ground water ranges from $5 \mathrm{mg} / \mathrm{l}$ to > $100 \mathrm{mg} / \mathrm{l}$, and due to its high solubility in water, nitrate has high mobility in the environment [7]. High levels of nitrates may promote mosquito production by enhancing proliferation of algal blooms and other microbial assemblages that serve as food for mosquito larvae $[9,10]$. Fertilizer application also may alter the physical and chemical properties of the aquatic habitats making them attractive oviposition sites for mosquitoes [11-13]. This may explain why fertilizer application in rice fields is often associated with a dramatic increase in mosquito larval populations [10-12]. However, experimental studies to decipher the impact of nitrogenous fertilizers on epidemiologically relevant mosquito life history traits in the absence of other confounding factors are lacking.

Pesticides may also affect mosquito populations and communities both directly and indirectly. When initially applied, pesticides have lethal effects but can break down over time and switch from being lethal to sublethal and eventually to having no effects [14]. A shift in pesticide concentrations from lethal to sublethal is clearly demonstrated by the rapid reduction in mosquito larvae and their predators after pesticide application, followed by the resurgence of mosquito populations thereafter since they recover faster than their predators $[15,16]$. Lethal concentrations of pesticide may produce compensatory effects by killing a fraction of the population and releasing the survivors from larval competition [17-19]. Conversely, insights from other aquatic insects and amphibians suggest that sublethal concentrations of insecticides can cause morphological, behavioral, and physiological impairments [20-24] that can become more deleterious when presented in the presence of other environmental stressors [24-26]. Similar effects have been reported in Culex and Aedes mosquitoes where larval exposure to certain pesticides alters their emergence rates, development time, longevity, body size, sex ratio, and vector competence $[18,27-30]$. In addition, Culex mosquitoes preferred to oviposit in carbarylcontaminated pools while Anopheles mosquitoes had no preference for either control or carbaryl-contaminated treatments [31].

We conducted a series of field and laboratory experiments to determine how Anopheles arabiensis and Culex quinquefasciatus mosquitoes respond to two commonly used pesticides ( $\alpha$ - cypermethrin and glyphosate) and two commonly used fertilizers (ammonium sulfate and diammonium phosphate). We examined this by quantifying several life history traits including oviposition site selection, development time, emergence rates, adult body size and longevity. Culex quinquefasciatus is a major worldwide vector of LF [32-34] while An. arabiensis is an important vector of both malaria and LF and has become the most dominant malaria vector in areas where insecticide-treated bed nets and indoor residual spraying have been implemented [35-37]. We tested the hypotheses that: (i) the fertilizer and pesticide treatments alter oviposition site selection by the two mosquito species; and (ii) agrochemical treatments would differentially affect the development time, emergence rates, adult body size and longevity of the two mosquito species.

\section{Methods \\ Study area}

This study was conducted at the Mwea Irrigation and Agricultural Development (MIAD) experimental station and at Kangichiri and Kariua villages in the Mwea rice irrigation scheme, $100 \mathrm{~km}$ north-east of Nairobi, in Mwea Division, Kenya. The two villages were selected based on the presence of large populations of An. arabiensis and $C x$. quinquefasciatus and proximity to MIAD. Mwea occupies the lower altitude zone of Kirinyaga County in an expansive lowlying area mainly characterized by black cotton soils. The mean annual rainfall is $950 \mathrm{~mm}$ with maximum amount falling in April-May (long rains) and October-November (short rains). The average maximum temperatures are in the range of $16-26.5{ }^{\circ} \mathrm{C}$. 
Relative humidity varies from 52 to $67 \%$. According to the 2009 national census, Mwea Division has approximately 150,000 persons in 25,000 households. The Mwea Rice Irrigation Scheme is located in the west central region of Mwea Division and covers an area of about 13,640 ha. More than $50 \%$ of the Scheme area is used for rice cultivation. The remaining area is used for subsistence farming, grazing and community activities. Anopheles arabiensis is the dominant vector of malaria in Mwea, and the only sibling species of the An. gambiae species complex recorded in the area $[38,39]$. Culex quinquefasciatus is the most abundant species of Culex in the area [40].

\section{Agrochemicals}

Alpha cypermethrin is a pyrethroid insecticide applied as an ultra-low volume spray to control insects in both large-scale commercial agriculture and small-scale agricultural settings. Pyrethroids are increasingly replacing organophosphates and carbamates in agriculture because of their effectiveness, lower application rates, and lower toxicity to mammals [41]. Up to $3,114 \mu \mathrm{g} / \mathrm{l}$ of permethrin have been observed in water bodies [42].

The herbicide glyphosate is of particular interest to understanding the consequences of pesticide use on pathogen transmission because of its widespread and abundant use [43]. By volume, it is one of the most widely used herbicides and is commonly used for agriculture, horticulture, viticulture and silviculture purposes, as well as garden maintenance [44]. Glyphosate is absorbed through foliage and minimally through roots and translocated throughout the plant [45]. Its primary action is blocking an enzyme that plants need to make aromatic amino acids and proteins thus killing the plants within days [46]. Worldwide, around 650,000 tons of glyphosate products were used in 2011 [47]. Glyphosate use has continued to increase largely due to the production of genetically modified crops and is expected to double by 2017 [48]. The maximum concentration of glyphosate observed in water bodies is $5,200 \mu \mathrm{g} / \mathrm{l}$ [49].

Ammonium sulfate $\left[\left(\mathrm{NH}_{4}\right)_{2} \mathrm{SO}_{4}\right]$ and diammonium phosphate $\left[\left(\mathrm{NH}_{4}\right)_{2} \mathrm{HPO}_{4}\right]$ are inorganic fertilizers that are commonly used to supplement the soil with three basic elements that are essential for plant growth nitrogen, sulfur and phosphorus. The annual world demand for nitrogen and phosphate fertilizers stands at 113.1 and 42.7 million tons, respectively and is expected to increase over the next two years [50]. These nutrients are important sources of ground and surface water pollution. Nitrate concentrations in water bodies near intensively cultivated and fertilized areas can be greater than $100 \mathrm{mg} / \mathrm{l}$ [51] while that of phosphate can be as high as $9.45 \mathrm{mg} / \mathrm{l}$ [52].
Laboratory studies on the effect of agrochemicals on oviposition site selection by An. arabiensis and CX. quinquefasciatus

Blood-engorged females of $A n$. arabiensis and $C x$. quinquefasciatus were collected inside human dwellings in Kangichiri and Kariua villages using manual aspirators. At MIAD, 20 randomly selected females of either species were transferred into one of 9 ( $A n$. arabiensis) and 15 (Cx. quinquefasciatus) insect rearing cages $(30 \times 30 \times 30 \mathrm{~cm})$ and provided continuous access to $10 \%$ sucrose. For Cx. quinquefasciatus oviposition, each cage was provisioned with five Petri dishes containing either $50 \mathrm{ml}$ of tap water (control) or $50 \mathrm{ml}$ of agrochemical-spiked water generating four treatments with a final concentration of $0.1 \mathrm{mg} /$ 1 - -cypermethrin, $0.5 \mathrm{mg} / \mathrm{l}$ glyphosate, $845 \mathrm{mg} / \mathrm{l}$ ammonium sulfate, or $845 \mathrm{mg} / \mathrm{l}$ diammonium phosphate. These pesticide concentrations are within the range that is commonly found in aquatic habitats $[42,49,51,52]$. In contrast, the fertilizer concentrations used in this study are much higher than observed in nature. Because fertilizer application in rice fields within the study sites and other parts of Africa is done manually through broadcasting, it is expected that some parts of the rice fields receive high doses of fertilizers similar to those used in this study. Therefore we sought to determine how potentially higher doses of fertilizers may affect mosquito ecology. A similar setup was used for An. arabiensis except that the Petri dishes were lined with filter papers moistened with respective agrochemical treatments. A single Petri dish was placed on each corner of a cage and the fifth one was placed in the middle of the cage. The treatments were rotated daily to eliminate positional bias. The number of eggs laid in each Petri dish were counted and recorded every day for 31 days and their sums computed. Agrochemicaltreated filter papers were replaced each day.

\section{Field studies on the effect of agrochemicals on oviposition site selection by Culex quinquefasciatus}

This experiment was conducted between 1st August, 2014 and 20th September, 2014 under field conditions since Culex egg rafts are easy to monitor compared to Anopheles eggs that are laid individually. The experiment was conducted in five randomly selected homesteads in Kangichiri village. In each homestead, five 20-litre plastic buckets containing either 31 of fermented grass infusion (control) or 31 of fermented grass infusion spiked with one of four agrochemicals for a final concentration of $1 \mathrm{mg} / \mathrm{l} \alpha$-cypermethrin, $2 \mathrm{mg} / \mathrm{l}$ glyphosate, $845 \mathrm{mg} / \mathrm{l}$ ammonium sulfate, or $845 \mathrm{mg} / \mathrm{l}$ diammonium phosphate served as the artificial oviposition sites. Because pesticides are expected to 
breakdown rapidly under field conditions, we deliberately used higher concentrations of $\alpha$-cypermethrin and glyphosate than those used in laboratory oviposition experiment described above. Each bucket had a top lid and large openings on their upper halves to facilitate access by mosquitoes. The infusion was prepared by mixing $1 \mathrm{~kg}$ of fresh grass with $100 \mathrm{l}$ of water and leaving it to ferment for 5 days. The homesteads were at least $60 \mathrm{~m}$ apart and the buckets within a homestead were $2 \mathrm{~m}$ apart. The buckets within each homestead were rotated daily to eliminate spatial effects. Every day, egg rafts were collected, counted, and transported to the laboratory in Petri dishes lined with moist filter papers. The infusion was replaced every three days and 13 oviposition trials were conducted.

\section{Effect of agrochemicals on survival and development of An. arabiensis and $C x$. quinquefasciatus}

Twenty first instar larvae (24 h old) of either An. arabiensis or $C x$. quinquefasciatus obtained by hatching eggs from control treatments of oviposition experiments were added into tripour beakers containing either $350 \mathrm{ml}$ of tap water (control) or $350 \mathrm{ml}$ of tap water spiked with one of four agrochemical treatments at the following final concentrations: $0.0004 \mathrm{mg} / \mathrm{l} \alpha$-cypermethrin, $0.05 \mathrm{mg} / \mathrm{l}$ glyphosate, $845 \mathrm{mg} / \mathrm{l}$ ammonium sulfate, or $845 \mathrm{mg} / \mathrm{l}$ diammonium phosphate. These low $\alpha$-cypermethrin and glyphosate concentrations were chosen based on concentrations observed in aquatic systems as well as in previous studies on the impact of sublethal doses of pesticides on aquatic communities. Also, our preliminary studies revealed that higher doses of $\alpha$-cypermethrin were lethal to mosquito larvae (data not shown). Each treatment was replicated 6 times for a total 60 containers. The larvae were replenished with 0.05 g ground Tetramin ${ }^{\bullet}$ baby fish food once per week. Containers were examined daily until all individuals had either pupated or died. Pupae were placed in plastic vials with a small volume of water until eclosion. The date and sex of newly eclosed adults in each replicate were recorded. The adults were held individually in $75 \times 20 \mathrm{~mm}$ plastic cups covered by nylon net and provided continuous access to $10 \%$ sucrose solution. All cages were maintained at approximately $25-27{ }^{\circ} \mathrm{C}$, with a relative humidity $(\mathrm{RH})$ of 65-75 \% and a 12:12 Light: Dark cycle. Each individual adult mosquito was monitored daily until death. Dead adults (both males and females) were preserved in plastic vials and transported to the Eastern and Southern Africa Centre of International Parasite Control (ESACIPAC), Kenya Medical Research Institute (KEMRI) where their wings were removed and mounted on microscope slides. The wings were scanned and measured from the tip (excluding the fringe) to the distal end of the allula, using VHX KEYENCE digital microscope at the Department of Entomology, Nairobi National Museum.

\section{Statistical analyses}

Data analyses were conducted using R.3.2.5 (R Core Team) and SAS 9.4 (SAS Institute) statistical packages. Data were checked for normality and homogeneity of variances using Kolmogorov-Smirnov test. Oviposition data were $\log$-transformed $[\log (x+1)]$ to normalize the distribution. The means of each replicate of a treatment were compiled for each life-history trait and statistical analyses were based on these means. For each mosquito species, univariate analysis of variance (ANOVA) was used to determine the effect of agrochemical treatments on oviposition site selection, hatching rates and emergence rates (males and females combined). In the field oviposition experiment, agrochemical treatment was used as a fixed factor while trial number was used as a random factor. Multivariate analysis of variance (MANOVA) was used to determine the effect of agrochemical treatments on both male and female development time, wing length and longevity. Standardized canonical coefficients were used to describe the relative contribution of development time, wing length, and longevity to the significant treatment effects. When significant effects were obtained in both ANOVA and MANOVA tests, pair-wise differences between treatment means were compared using the Tukey-Kramer multiple comparison procedure.

\section{Results}

Effect of agrochemicals on oviposition site selection by An. arabiensis and $C x$. quinquefasciatus

Agrochemical treatments had significant effects on oviposition site selection by $A n$. arabiensis $\left(F_{(4,40)}=24.02\right.$, $P<0.001)$. The numbers of $A n$. arabiensis eggs deposited were highest in the DAP and ammonium sulfate treatments, intermediate in the control treatment and lowest in the cypermethrin and glyphosate treatments (Fig. 1a). Similarly, results of both laboratory $\left(F_{(4,70)}=25.18, P<0.001\right)$ and field experiments $\left(F_{(4,1245)}=331.37, P<0.001\right)$ revealed that $C x$. quinquefasciatus egg rafts were highest in the DAP and ammonium sulfate treatments, intermediate in the control treatment, and lowest in the cypermethrin and glyphosate treatments (Fig. 1b, c).

Effect of agrochemicals on emergence rates, development time, wing length and longevity of $A n$. arabiensis and $C_{X}$. quinquefasciatus

Agrochemical treatments had significant effects on emergence rates of both mosquito species (An. arabiensis: $F_{(4,25)}=4.28, P=0.009 ; C x$. quinquefasciatus: $F_{(4,25)}=4.54$, $P=0.007)$. Emergence rates for An. arabiensis in the cypermethrin treatment were significantly lower compared to those of the control and ammonium sulfate but not glyphosate and DAP treatments (Fig. 2a). Emergence rates for $C x$. quinquefasciatus in the cypermethrin and glyphosate 

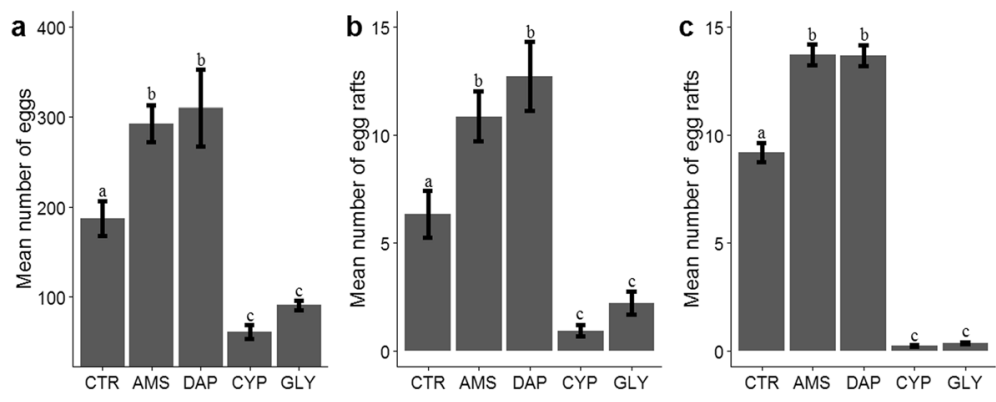

Fig. 1 Mean number ( \pm standard error, SE) of An. arabiensis eggs $(\mathbf{a})$ and $C$. quinquefasciatus egg rafts $(\mathbf{b}$, $\mathbf{c}$ ) laid in different agrochemical treatments (b and $\mathbf{c}$ are results for laboratory and field experiments, respectively). Different lower case letters indicate significant differences between treatments. Abbreviations: CTR, control; AMS, ammonium sulfate; DAP, diammonium phosphate; CYP, cypermethrin; GLY, glyphosate

treatments were significantly lower than those of DAP but not control and ammonium sulfate treatments (Fig. 2a).

For both mosquito species and sexes, multivariate analysis of variance revealed a significant effect of agrochemical treatment on development time to adulthood, wing length and longevity, with development time followed by wing length accounting for most of the variation (Table 1). Anopheles arabiensis females from the control, DAP, and ammonium sulfate treatments had significantly longer development times compared to those from the glyphosate and cypermethrin treatments $\left(F_{(4,25)}=17.71, \quad P<0.001\right.$; Fig. $\left.2 \mathrm{~b}\right)$. However, agrochemical treatment had no significant effect on $A n$. arabiensis female wing length $\left(F_{(4,25)}=3.2, \quad P=0.30\right.$; Fig. $2 \mathrm{~d})$ and longevity $\left(F_{(4,25)}=1.6, P=0.21\right)$. Anopheles arabiensis males from the DAP and ammonium sulfate treatments had significantly longer development times compared to those from the control, glyphosate and cypermethrin treatments $\left(F_{(4,25)}=16.36, \quad P<0.001\right.$; Fig. 2c). Anopheles arabiensis males from the ammonium sulfate treatment were significantly smaller compared to those from the control, glyphosate and cypermethrin treatments, but not from the DAP treatment $\left(F_{(4,25)}=6.32, P=\right.$ 0.001; Fig. 2e). In addition, males from the DAP treatment were significantly smaller than those from the cypermethrin treatments (Fig. 2e). There were no significant effects of agrochemical treatment on $A n$. arabiensis male longevity $\left(F_{(4,25)}=1.05, P=0.40\right)$.

Culex quinquefasciatus females from the control, DAP, and ammonium sulfate treatments took longer to develop

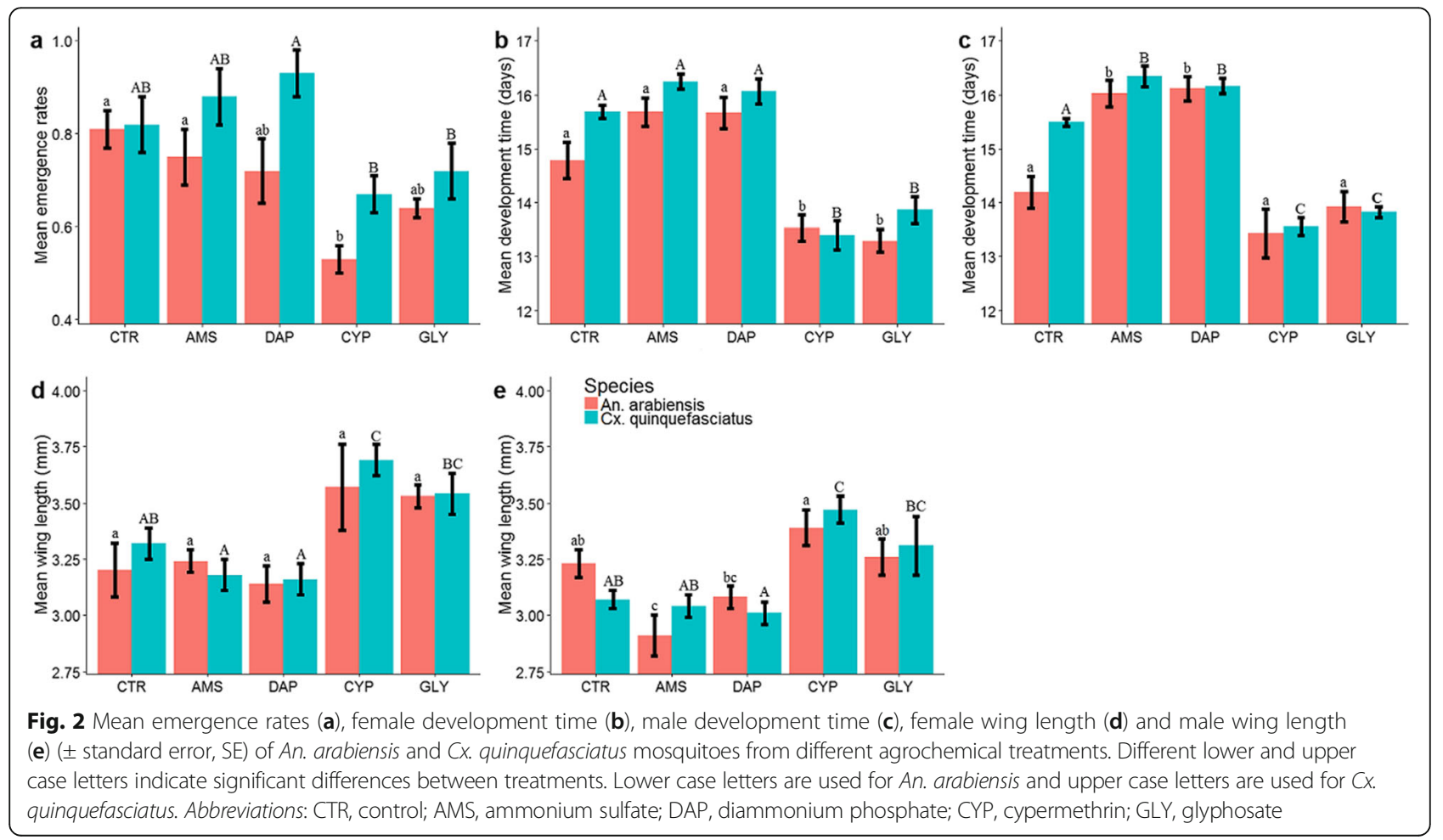


Table 1 MANOVA results on the effect of agrochemical treatments on development time to adulthood, wing length, and longevity of An. arabiensis and Cx. quinquefasciatus mosquitoes. Standardized canonical coefficients (SCC) describe the relative contribution of each response variable to significant treatment effects. Negative associations are denoted by (-)

\begin{tabular}{llllllll}
\hline Mosquito species & Sex & $d f$ & Pillai's trace & $P$ & \multicolumn{3}{l}{ Standardized canonical coefficients } \\
\cline { 6 - 8 } & & & & DT & WL & LG \\
\hline An. arabiensis & Females & 12,75 & 0.90 & 0.005 & 1.68 & -0.44 & -0.06 \\
& Males & 12,75 & 1.07 & 0.0004 & -1.67 & 1.13 & 0.16 \\
CX. quinquefasciatus & Females & 12,75 & 0.96 & 0.002 & -2.55 & 0.63 & -0.38 \\
& Males & 12,75 & 1.22 & $<0.001$ & -3.36 & 0.56 & 0.15 \\
\hline
\end{tabular}

Abbreviations: $d f$ degrees of freedom, DT development time to adulthood, WL wing length of adult, $L G$ longevity

compared to those from the glyphosate and cypermethrin treatments $\left(F_{(4,25)}=39.24, \quad P<0.001\right.$; Fig. 2b). Culex quinquefasciatus females from the DAP and ammonium sulfate treatments were significantly smaller compared to those from the glyphosate and cypermethrin treatments but not from the control $\left(F_{(4,25)}=10.01, P<0.001\right.$; Fig. 2 d). Females from the control treatments were also significantly smaller than those from the cypermethrin but not the glyphosate treatment (Fig. 2d). There were no significant effects of agrochemical treatment on $C x$. quinquefasciatus female longevity $\left(F_{(4,25)}=0.77, P=0.55\right)$. Culex quinquefasciatus male development time was longest in DAP and ammonium sulfate treatments, intermediate in control treatments, and shortest in glyphosate and cypermethrin treatments $\left(F_{(4,25)}=84.99, P<0.001\right.$; Fig. 2c) . Males from the DAP treatment were significantly smaller than those from the glyphosate and cypermethrin treatments but not from the control and ammonium sulfate treatments $\left(F_{(4,25)}=7.99, P<0.001\right.$; Fig. $\left.2 \mathrm{e}\right)$. In addition, males from the control treatment were significantly smaller than those from the cypermethrin treatment (Fig. 2e).

\section{Discussion}

Our results show that agrochemicals can alter the attractiveness and quality of $A n$. arabiensis and $C x$. quinquefasciatus larval habitats. When presented a choice of fertilizer and pesticide-treated oviposition substrates, gravid females of both mosquito species preferentially oviposited in fertilizer-treated substrates. Fertilizer treatments were also associated with higher emergence rates, longer development times, and smaller adults relative to pesticide treatments. These findings are partially consistent with the optimal oviposition theory which predicts that egg laying females should select oviposition sites that maximize the probability for their offspring to reach adulthood and reproduce [53, 54]. To the best of our knowledge, this is the first study to investigate how commonly used agrochemicals affect oviposition site selection and offspring survival of two of the most important mosquito vectors of human pathogens in sub-Saharan Africa.
The impact of fertilizers on mosquito larval populations is well documented. Application of nitrogenous fertilizers in rice fields is often associated with dramatic increase in larval populations of Anopheles and Culex mosquitoes [9-12, 38]. Similarly, fertilizerenriched mesocosms and wetlands had higher populations of mosquito larvae compared to control treatments $[55,56]$. However, the mechanisms underlying fertilizer-mediated increase in mosquito larval populations are poorly understood. Our results suggest that fertilizer-mediated enhancement of habitat attractiveness and quality may be two of the major factors that account for dramatic increase in mosquito larval populations following application of nitrogenous fertilizers. Fertilizer application promotes microbial growth, which provide chemical cues that aid gravid females to locate suitable oviposition sites [57, 58], stimulate egg hatch [59], and serves as food for mosquito larvae [60],

Avoidance of pesticide-treated oviposition substrates by the two mosquito species was expected as pesticides could be detrimental for egg and larval survival. However, previous studies have documented both positive and negative effects of pesticides on oviposition site selection by mosquitoes. Aedes aegypti avoided ovipositing in grass infusion treated with microbial larvicide Bacillus thuringiensis var. israelensis but did not discriminate between tap water or untreated grass infusion [61]. Gravid females of Aedes aegypti were attracted to spinosad-treated oviposition substrates but avoided temephos-treated substrates [62] Similarly, Eugenol, citronellal, thymol, pulegone, rosemary oil, and cymene acted as oviposition deterrents for Ae. aegypti while borneol, camphor and $\beta$-pinene acted as oviposition attractants for this mosquito species [63]. Carbaryl-treated pools were more attractive oviposition sites for Culex mosquitoes but had no effect on oviposition behavior of Anopheles mosquitoes [31]. Collectively, these findings suggest that pesticides can alter oviposition behavior of mosquitoes but the direction of the response is pesticide-specific. Further studies are needed to establish how a variety of mosquito species respond to different types of commonly used pesticides. 
In general, mosquitoes from control and fertilizer treatments took longer to develop and were smaller compared to those from pesticide treatments. Given that pesticide treatments had lower emergence rates compared to control and fertilizer treatments, we believe that random elimination of some larvae by pesticides may have released the survivors from larval competition thereby promoting faster development and larger mosquitoes. It is also possible that pesticides may have selectively favored the survival of larger individuals with rapid growth and development. Both mechanisms have been used to explain why Aedes and Culex mosquitoes from experimental microcosms exposed to low concentrations of pesticides develop faster and are larger compared to those from control treatments $[18,29,64]$. However, our study design could not allow us to determine which of the two mechanisms was responsible for our observation and further research is needed on this topic.

Mosquito body size is commonly used as a proxy for mosquito fitness and vector potential. Large mosquitoes consume bigger blood meals and lay more eggs compared to small mosquitoes [65]. Large mosquitoes also have longer life spans [2] and are more likely to survive through the extrinsic incubation period of the pathogen compared to smaller mosquitoes [66]. Thus, although fertilizer application may lead to production of large numbers of adult mosquitoes, this may not necessarily translate to increased risk of pathogen transmission since the majority of adults may be small and short-lived. This may be one of the many factors explaining why rice cultivation in East Africa is often associated with large populations of malaria vectors but lower risk of malaria transmission compared to adjacent non-irrigated agroecosystems [67-70]. However, we did not observe any significant effect of agrochemical treatments on adult mosquito life span. Moreover, both fertilizers and pesticides are used simultaneously in many agroecosystems and the large mosquitoes resulting from pesticide treatments may have higher fecundity [64] and longevity both of which may increase the risk of pathogen transmission. However, although exposure of mosquitoes to sublethal concentrations of pesticides is known to enhance arbovirus transmission [28, 29], their impact on malaria and LF transmission is poorly understood. Studies using insecticide-resistant and insecticide-susceptible strains of mosquitoes suggest that exposure to pesticides may reduce the ability of the vector to transmit malaria and LF [71-73] but additional studies are needed to assess how short-term exposure of mosquitoes to sublethal pesticide concentrations affect vector susceptibility to malaria and LF parasites.

\section{Conclusions}

Our results demonstrate that the extensive and widespread use of agricultural chemicals to promote agricultural production can have unexpected consequences on human health by altering epidemiologically relevant mosquito life history traits. In particular, we found that agrochemical treatments can influence where mosquitoes lay eggs, how long they take to complete their development, how many adult mosquitoes are produced, and how big the resulting adults will be. In turn, these traits can influence the spatial and temporal distribution and abundance of mosquito populations and associated pathogens. Additional studies on sublethal effects of agricultural chemicals on mosquitoes and the public health implications are warranted and concerted efforts made to mitigate any potential negative effects of agrochemical use on mosquito-borne diseases.

\section{Abbreviations \\ DT, Development time; WL, Wing length; LG, Longevity; df, Degrees of freedom; CTR, Control; AMS, Ammonium sulfate; DAP, Diammonium phosphate; CYP, Cypermethrin; GLY, Glyphosate; ESACIPAC, Eastern and Southern Africa Centre of International Parasite Control; KEMRI, Kenya Medical Research Institute; LF, Lymphatic filariasis; mg/l, Milligrams per liter; MIAD, Mwea Irrigation and Agricultural Development; $\left(\mathrm{NH}_{4}\right)_{2} \mathrm{HPO}_{4}$, Diammonium phosphate; $\left(\mathrm{NH}_{4}\right)_{2} \mathrm{SO}_{4}$, Ammonium sulfate; $\mathrm{RH}$, Relative humidity}

\section{Acknowledgments}

We thank James Wauna, Peter Mutiga, Nelson Maingi, Henry Kanyi, Morris Mutua, and Irene Kamau for their technical assistance. We are also grateful to Raphael Wanjogu, Mwea Irrigation and Agricultural Development Centre (MIAD), and Laban Njoroge, Entomology Laboratory, Nairobi National Museum for allowing us to use their laboratory facilities. This paper is published with the permission of the Director, Kenya Medical Research Institute.

\section{Funding}

This work was supported by start-up funds from Illinois Natural History Survey, University of Illinois to EJM.

\section{Availability of data and materials}

The data supporting the conclusions of this article are included within the article. The raw data from this study has not been shared at this time because we anticipate an additional publication exploring the relationship between pesticide-mediated changes in aquatic microbial communities and mosquito performance.

\section{Authors' contributions}

TWK, SMN, and EJM designed and coordinated the study. TWK collected the data. TWK and EJM analyzed the data and wrote the manuscript. SMN and AKM reviewed the manuscript. All authors read and approved the final manuscript.

\section{Competing interests}

The authors declare that they have no competing interests.

\section{Consent for publication}

Not applicable.

Ethics approval and consent to participate

Not applicable.

\section{Author details}

${ }^{1}$ Institute of Tropical Medicine, Jomo Kenyatta University of Agriculture and Technology, Nairobi, Kenya. ${ }^{2}$ Eastern and Southern Africa Centre of International Parasite Control, Kenya Medical Research Institute, Nairobi, Kenya. ${ }^{3}$ College of Health Sciences, Jomo Kenyatta University of Agriculture and Technology, Nairobi, Kenya. ${ }^{4}$ Illinois Natural History Survey, Prairie Research Institute, University of Illinois, Champaign, USA. ${ }^{5}$ Present Address: U.S.D.A., Agricultural Research Service, National Center for Agricultural Utilization Research, Crop Bioprotection Research Unit, 1815 N. University St., Peoria, IL 61604, USA. 
Received: 29 March 2016 Accepted: 2 September 2016 Published online: 13 September 2016

\section{References}

1. Alto BW, Lounibos LP, Higgs S, Juliano SA. Larval competition differentially affects arbovirus infection in Aedes mosquitoes. Ecol. 2005;86:3279-88.

2. Reiskind MH, Lounibos LP. Effects of intraspecific larval competition on adult longevity in the mosquitoes Aedes aegypti and Aedes albopictus. Med Vet Entomol. 2009;23:62-8

3. Reiskind MH, Wilson ML. Culex restuans (Diptera: Culicidae) oviposition behavior determined by larval habitat quality and quantity in southeastern Michigan. J Med Entomol. 2004:41:179-86.

4. Bentley MD, Day JF. Chemical ecology and behavioral aspects of mosquito oviposition. Ann Rev Entomol. 1989;34:401-21.

5. Grube A, Donaldson D, Kiely T, Wu L. Pesticide industry sales and usage: 2006 and 2007 market estimates. Washington, DC: U.S. Environmental Protection Agency; 2011.

6. FAO. Current world fertilizer trends and outlook to 2016. Rome: Food and Agriculture Organization of the United Nations; 2012.

7. Bogardi I, Kuzelka RD, Ennenga WG. Nitrate contamination: exposure, consequence, and control, vol. 30. New York: Springer; 1991. p. 333-47.

8. Gilliom RJ, Barbash JE, Crawford CG, Hamilton PA, Martin JD, Nakagaki N, et al. The quality of our nation's waters-pesticides in the nation's streams and ground water, 1992-2001. USA: Geological Survey Circular; 2007.

9. Sunish IP, Raghunatha Rao D, Gajanana A. Nitrogenous fertilizers, neem and vectors of Japanese encephalitis virus. Current Scie. 1998:75:1107.

10. Victor TJ, Reuben R. Effects of organic and inorganic fertilisers on mosquito populations in rice fields of southern India. Med Vet Entomol. 2000;14:361-8.

11. Mutero C, Ng'ang'a P, Wekoyela P, Githure J, Konradsen F. Ammonium sulphate fertiliser increases larval populations of Anopheles arabiensis and culicine mosquitoes in rice fields. Acta Trop. 2004;89:187-92.

12. Muturi EJ, Mwangangi JM, Shililu J, Muriu S, Jacob B, Kabiru E, et al. Mosquito species succession and the physicochemical factors affecting their abundance in rice fields in Mwea, Kenya. J Med Entomol. 2007:44:336-44.

13. Sunish IP, Rajendran $R$, Reuben $R$. The role of urea in the oviposition behaviour of Japanese encephalitis vectors in rice fields of South India. Mem Inst Oswaldo Cruz. 2003;98:789-91.

14. Relyea R, Hoverman JT. Assessing the ecology in ecotoxicology: a review and synthesis in freshwater systems. Ecol Lett. 2006;9:1157-71.

15. Roger PA, Simpson I, Oficial R, Ardales S, Jimenez R. Effects of pesticides on soil and water microflora and mesofauna in wetland ricefields - a ummary of current knowledge and extrapolation to temperate environments. Australian J Exptal Agric. 1994;34:1057-68.

16. Service MW. Mortalities of the immature stages of species B of Anopheles gambiae complex in Kenya: comparison between ricefields and temporary pools, identification of predators, and effects of insecticidal spraying. J Med Entomol. 1977;13:535-45.

17. Juliano SA. Population dynamics. J Am Mosq Control Assoc. 2007;23:265-75.

18. Muturi EJ, Costanzo K, Kesavaraju B, Lampman R, Alto BW. Interaction of a pesticide and larval competition on life history traits of Culex pipiens. Acta Trop. 2010;116:141-6.

19. Darriet F, Rossignol M, Chandre F. The combination of NPK fertilizer and deltamethrin insecticide favours the proliferation of pyrethroid-resistant Anopheles gambiae (Diptera; Culicidae). Parasit Vectors. 2012;19(2):159-64.

20. Campero M, Slos S, Ollevier F, Stoks R. Sub lethal pesticide concentrations and predation jointly shape life history: behavioral and physiological mechanisms. Ecol Appl. 2007;17:2111-22.

21. Pestana JL, Alexander AC, Culp JM, Baird DJ, Cessna AJ, Soures AM. Structural and functional responses of benthic invertebrates to imidacloprid in outdoor stream mesocosms. Environ Pollut. 2009;157:2328-34.

22. Pestana JL, Loureiro S, Baird DJ, Soares AM. Fear and loathing in the benthos: Responses of aquatic insect larvae to the pesticide imidacloprid in the presence of chemical signals of predation risk. Aquat Toxicol. 2009;93:138-49

23. Relyea RA. New effects of Roundup on amphibians: predators reduce herbicide mortality; herbicides induce antipredator morphology. Ecol Appl. 2012:22:634-47.

24. Woodley SK, Mattes BM, Yates EK, Relyea RA. Exposure to sub lethal concentrations of a pesticide or predator cues induces changes in brain architecture in larval amphibians. Oecologia. 2015;179:655-65.
25. Relyea RA. Predator cues and pesticides: A double dose of danger for amphibians. Ecol App. 2003;13:1515-21.

26. Relyea RA. Synergistic impacts of malathion and predatory stress on six species of North American tadpoles. Environ Toxicol Chem. 2004:23:1080-4.

27. Bara JJ, Montgomery A, Muturi EJ. Sub lethal effects of atrazine and glyphosate on life history traits of Aedes aegypti and Aedes albopictus (Diptera: Culicidae). Parasitol Res. 2014;113:2879-86.

28. Muturi EJ, Alto BW. Larval environmental temperature and insecticide exposure alter Aedes aegypti competence for arboviruses. Vector Borne Zoonot Dis. 2011;11:1157-63.

29. Muturi EJ, Costanzo K, Kesavaraju B, Alto BW. Can pesticides and larval competition alter susceptibility of Aedes mosquitoes (Diptera: Culicidae) to arbovirus infection? J Med Entomol. 2011:48:429-236.

30. Muturi EJ, Lampman R, Costanzo K, Alto BW. Effect of temperature and insecticide stress on life-history traits of Culex restuans and Aedes albopictus (Diptera: Culicidae). J Med Entomol. 2011;48:243-50.

31. Vonesh JR, Buck JC. Pesticide alters oviposition site selection in gray treefrogs. Oecologia. 2007;154:219-26.

32. Muturi EJ, Mbogo CM, Mwangangi JM, Ng'ang'a ZW, Kabiru EW, Mwandawiro C, Beier JC. Concomitant infections of Plasmodium falciparum and Wuchereria bancrofti on the Kenyan coast. Filaria J. 2006:5:8.

33. Mwandawiro C, Fujimaki Y, Mitsui Y, Katsivo M. Mosquito vectors of bancroftian filariasis in Kwale district Kenya. East Afri Med J. 1997;74:288-93.

34. Wijers DJB, Kiilu G. Bancroftian filariasis in Kenya III. Entomological investigations in Mambrui, a small coastal town, and Jaribuni, a rural area more inland (Coast Province). Ann Trop Med Parasitol. 1977;71:347-59.

35. Bayoh MN, Mathias DK, Odiere MR, Mutuku FM, Kamau L, Gimnig JE, et al. Anopheles gambiae: historical population decline associated with regional distribution of insecticide-treated bed nets in western Nyanza Province. Kenya Malar J. 2010;9:62.

36. Mwangangi JM, Mbogo CM, Orindi BO, Muturi EJ, Midega JT, Nzovu J, et al. Shifts in malaria vector species composition and transmission dynamics along the Kenyan coast over the past 20 years. Malar J. 2013;12:13.

37. Sinka ME, Golding N, Massey NC, Wieba A, Huang Z, Hay SI, Moyes CL. Modelling the relative abundance of the primary African vectors of malaria before and after the implementation of indoor, insecticide-based vector control. Malar J. 2016;15:142.

38. Mutero CM, Blank H, Konradsen F, Hoek W. Water management for controlling the breeding of Anopheles mosquitoes in rice irrigation schemes in Kenya. Acta Trop. 2000;76:253-6.

39. Muturi EJ, Kim CH, Baliraine FN, Musani S, Jacob B, Githure J, Novak RJ. Population genetic structure of Anopheles arabiensis (Diptera: Culicidae) in a rice growing area of central Kenya. J Med Entomol. 2010;47:144-51.

40. Muturi EJ, Shililu J, Jacob B, Gu W, Githure J, Novak R. Mosquito species diversity and abundance in relation to land use in a riceland agroecosystem in Mwea, Kenya. J Vector Ecol. 2006;31:129-37.

41. Solomon KR, Giddings JM, Maund SJ. Probabilistic risk assessment of cotton pyrethroids: 1. Distributional analyses of laboratory aquatic toxicity data. Environ Toxicol Chem. 2001:20:652-9.

42. Norris LA, Lorz HW, Gregory SV. Influence of forest and range land management on anadromous fish habitat in western North America: forest chemicals. PNW-GTR-149. Gen. Tech. Rep. USDA. Forest Service, Pacific Northwest Forest and Range Experiment Station. 1983. p. 95.

43. Kelly DW, Poulin P, Tompkins DM, Townsend CR. Synergistic effects of glyphosate formulation on parasite infection on fish malformations and survival. J Appl Ecol. 2010;47:498-504.

44. Garthwaite DG, Barker I, Parrish G, Smith L, Chippindale C, Petravalle S. Pesticide Usage Survey Report 235- Arable crops in The United Kingdom 2010. London: DEFRA; 2011.

45. Franz JE, Mao MK, Sikorski JA. Glyphosate: A unique global herbicide. Am Chem Soc Chap. 1997:4:65-97.

46. Della-Cioppa G, Bauer SC, Klein BK, Shah DM, Fraley RT, Kishore GM. Translocation of the precursor of 5-enolpyruvylshikimate-3-phosphate synthase into chloroplasts of higher plants in vitro. Proc Natl Acad Sci U S A. 1986;83:6873-7.

47. CCM International. Outlook for China glyphosate Industry 2012-2016. 2011.

48. Global Industry Analyst. Global Glyphosate Market to reach 1.35 metric tons by 2017; According to a new report by global industry Analysts. Inc. Press Release 10 October 2011.

49. Edwards WM, Triplett GB, Kramer RM. A watershed study of glyphosate transport in runoff. J Environ Qual. 1980;9:661-5. 
50. FAO. World fertilizer trends and outlook to 2018. Rome: FAO; 2015.

51. George HR. The impacts of agricultural chemicals on ground water quality. Geojournal. 1987;15(3):283-95.

52. Belagali DJ. Impact of chemical fertilizers on water quality in selectd agricultural areas of Mysote district, Karnataka, India. Inter J Envtal Scie. 2012;2:1450-8.

53. Craig TP, Itami JK, Price PW. A Strong relationship between oviposition preference and larval performance in a shoot-galling sawfly. Ecol. 1989;70:1691-9.

54. Blaustein L, Kotler B. Oviposition habitat selection by the mosquito, Culiseta Iongiareolata: Effects of conspecifics, food and green toad tadpoles. Ecol Entomol. 1993;18:104-8.

55. Duguma D, Walton WE. Effects of nutrients on mosquitoes and an emergent macrophyte, Schoenoplectus maritimus, for use in treatment wetlands. J Vector Ecol. 2014:39:1-13.

56. Young GB, Golladay S, Covich A, Blackmore M. Nutrient enrichment affects immature mosquito abundance and species composition in field-based mesocosms in the coastal plain of Georgia. Environ Entomol. 2014;43:1-8.

57. Ponnusamy L, Xu N, Nojima S, Wesson DM, Schal C, Apperson CS. Identification of bacteria and bacteria-associated chemical cues that mediate oviposition site preferences by Aedes aegypti. Proc Natl Acad Sci USA. 2008:105:9262-7.

58. Ponnusamy L, Wesson DM, Arellano C, Schal C, Apperson CS. Species composition of bacterial communities influences attraction of mosquitoes to experimental plant infusions. Microb Ecol. 2010;59:158-73.

59. Ponnusamy L, Boroczky K, Wesson DM, Schal C, Apperson CS. Bacteria stimulate hatching of yellow fever mosquito eggs. PLoS One. 2011;6:e24409.

60. Merritt RW, Dadd RH, Walker ED. Feeding behavior, natural food, and nutritional relationships of larval mosquitoes. Annu Rev Entomol. 1992;37:349-76.

61. Santos SRA, Melo-Santos MAV, Regis L, Albuquerque CMR. Field evaluation of ovitraps consociated with grass infusion and Bacillus thuringiensis var. israelensis to determine oviposition rates of Aedes aegypti. Dengue Bulletin 2003;27:156-62.

62. Quiroz-Martinez H, Garza-Rodriguez MI, Trujillo-Gonzalez Ml, Zapeda-Cavazos IG, Siller-Aguillon I, Martinez-Perales JF, Rodriguez-Castro VA. Selection of oviposition sites by female Aedes aegypti exposed to two larvicides. J Am Mosq Control Assoc. 2012;28:47-9.

63. Waliwitiya R, Kennedy CJ, Lowenberger CA. Larvicidal and ovipositionaltering activity of monoterpenoids, trans-anithole and rosemary oil to the yellow fever mosquito Aedes aegypti (Diptera: Culicidae). Pest Manag Sci. 2009:65:241-8.

64. Muturi EJ. Larval rearing temperature influences the effect of malathion on Aedes aegypti life history traits and immune responses. Chemosphere. 2013;92:1111-6.

65. Briegel H. Metabolic relationship between female body size, reserves, and fecundity of Aedes aegypti. J Insect Physiol. 1990;36:165-72.

66. Bara J, Rapti Z, Caceres CE, Muturi EJ. Effect of larval competition on extrinsic incubation period and vectorial capacity of Aedes albopictus for dengue virus. PLoS One. 2015;10(5):e0126703.

67. Ijumba J, Lindsay S. Impact of irrigation on malaria in Africa: paddies paradox. Med Vet Entomol. 2001;15:1-11.

68. Ijumba J, Mosha F, Lindsay S. Malaria transmission risk variations derived from different agricultural practices in an irrigated area of northern Tanzania. Med Vet Entomol. 2002;16:28-38.

69. ljumba JN, Shenton FC, Clarke SE, Mosha FW, Lindsay SW. Irrigated crop production is associated with less malaria than traditional agricultural practices in Tanzania. Trans Roy Soc Trop Med Hyg. 2002;96:476-80.

70. Mutero C, Kabutha C, Kimani V, Kabuage L, Gitau G, Ssennyonga J, et al. A transdisciplinary perspective on the links between malaria and agroecosystems in Kenya. Acta Trop. 2004:89:171-86.

71. McCarroll L, Hemingway J. Can insecticide resistance status affect parasite transmission in mosquitoes? Insect Biochem Mol Biol. 2002;32:1345-51.

72. Ferguson HM, Maire N, Takken W, Lyimo IN, Briet O, Lindsay SW, Smith TA. Selection of mosquito life-histories: a hidden weapon against malaria? Malar J. 2012;11:106

73. Alout H, Djegbe I, Chandre F, Djogbenou LS, Dabire RK, Corbel V, Cohuet A. Insecticide exposure impacts vector-parasite interactions in insecticide-resistant malaria vectors. Proc Roy Soc B-Biological Scie. 2014;281.

\section{Submit your next manuscript to BioMed Central and we will help you at every step:}

- We accept pre-submission inquiries

- Our selector tool helps you to find the most relevant journal

- We provide round the clock customer support

- Convenient online submission

- Thorough peer review

- Inclusion in PubMed and all major indexing services

- Maximum visibility for your research

Submit your manuscript at www.biomedcentral.com/submit
C Biomed Central 